\title{
Una mirada a las prácticas de lectura y de escritura en la enseñanza de la lengua francesa en instituciones educativas oficiales y privadas de Bogotá
}

A review to the pedagogical reading and writing practices in French language teaching in official and private institutions of Bogotá

\section{Un regard sur les pratiques de lecture et d'écriture dans l'enseignement de la langue française dans les établissements d'enseignement officiels et privés de Bogotá}

Nelly Bayona Ballesteros*, Marisella Buitrago Ramírez**; Carlos Fernando Herrera Castiblanco ${ }^{\text {****:* }}$ y Jorge Peña Mendoza ${ }^{* * * * * *}$

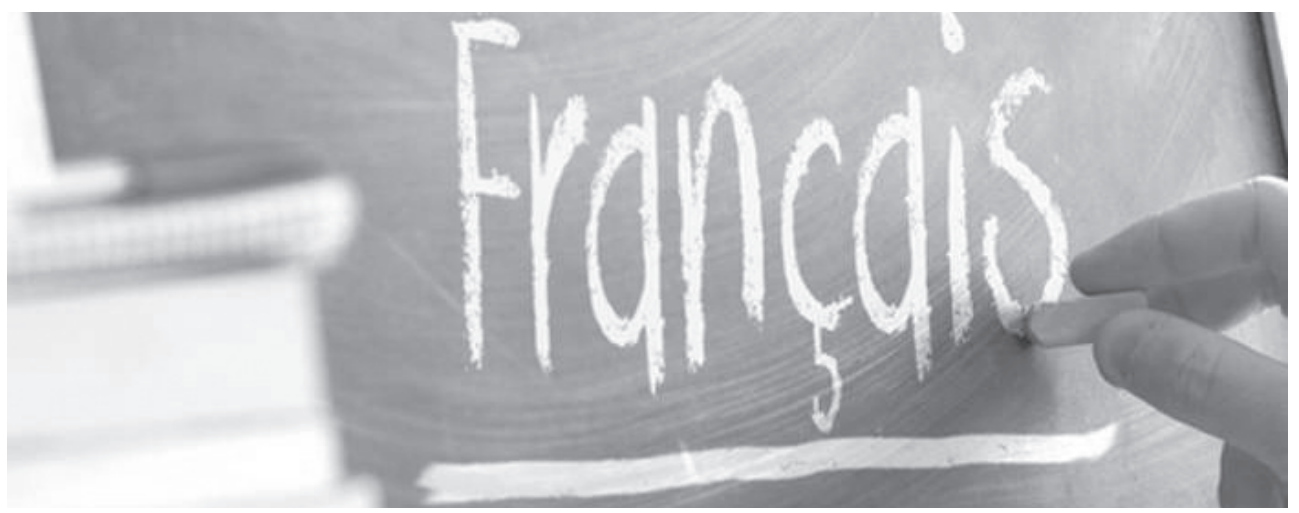

Citar este artículo como: Bayona Bellesteros, N., Buitrago Ramírez, M., Herrera Castiblanco, C. F. y Peña Mendoza, J. (2017). Una mirada a las prácticas de lectura y de escritura en la enseñanza de la lengua francesa en instituciones educativas oficiales y privadas de Bogotá. Revista Papeles, 9(17), 23-30.

Fecha de recibido: 15 de marzo de 2017.

Fecha de aceptación: 10 de mayo de 2017.

* Magíster en Didáctica del Francés como Lengua Extranjera de la Universidad del Rosario. Licenciada en Lenguas Mayores Inglés y Francés de la Universidad Pedagógica Nacional. Docente de lenguas de la Licenciatura en Lengua Castellana e Inglés en la Facultad de Educación de la Universidad Antonio Nariño. Asesora de trabajos de grado y miembro del grupo de investigación Culturas Universitarias de esta institución. Correo electrónico: nebayona@uan.edu.co

** Candidata a doctora en la línea de investigación Civilizaciones, culturas, literaturas y sociedades. Estudios Romanos Españoles en la Universidad Paris-Sorbonne IV. Magistra en Educación con énfasis en Sistemas Didácticos del Lenguaje de la Pontificia Universidad Javeriana. Licenciada en Español y Lenguas Extranjeras en la Universidad Pedagógica Nacional y profesora titular e investigadora educativa de la Universidad Antonio Nariño. Correo electrónico: marisbuitrago@uan.edu.co

*:*: Magíster en Literatura Hispanoamericana del Instituto Caro y Cuervo de Bogotá. Licenciado en Filología e Idiomas de la Universidad Libre de Bogotá. Docente de lenguas de la Universidad Antonio Nariño. Asesor de 


\title{
Resumen
}

Este artículo reflexiona sobre las prácticas pedagógicas de lectura y de escritura relacionadas con la situación actual de la enseñanza de la lengua francesa en colegios oficiales y privados de la ciudad de Bogotá, Colombia. Desde esa perspectiva, se presenta un panorama general sobre dichas prácticas para adentrarse en cómo los docentes vienen promoviendo el desarrollo de competencias vinculadas a las dos habilidades mencionadas. Se propone la incorporación de nuevos y diversos métodos, mediaciones y estrategias de aprendizaje, atendiendo a la población, los intereses tanto individuales como colectivos, la modalidad institucional, entre otros factores que inciden en la enseñanza del francés. Es así como el docente asume el papel de guía y facilitador en el fomento de experiencias que generan en el estudiante un auténtico interés en el aprendizaje de la lengua extranjera.

Palabras clave: lectura, escritura, métodos, mediaciones, estrategias de aprendizaje.

\begin{abstract}
This article reflects on the pedagogical practices of reading and writing in relation to the current situation of teaching French in official and private schools in Bogotá, Colombia. From this perspective, an overview is presented on these pedagogical practices to go into how teachers are promoting the development of competences linked to the two skills mentioned. The text proposes the incorporation of new and diverse methods, mediations and learning strategies, taking into account the learners, both individual and collective interests, institutional modalities, among other factors that influence the teaching of French. This is how the teacher assumes the role of guide and facilitator in the promotion of experiences that generate in the student a genuine interest in learning the foreign language.
\end{abstract}

Keywords: reading, writing, methods, mediations, learning strategies.

\section{Résumé}

Cet article réfléchit sur les pratiques pédagogiques de la lecture et de l'écriture par rapport à la situation actuelle de l'enseignement de la langue française dans les écoles officiels et privées de Bogotá, en Colombie. Dans cette perspective, on présente un panorama sur ces pratiques pédagogiques pour approfondir la manière dont les enseignants favorisent le développement des compétences liées aux deux habiletés mentionnées. On propose que des méthodes nouvelles et diverses, des médiations et des stratégies d'apprentissage soient intégrées en tenant en compte les élèves, les intérêts individuels et collectifs, la modalité institutionnelle, entre autres facteurs qui influencent l'enseignement du français. C'est ainsi que l'enseignant assume le rôle de guide et de facilitateur dans la promotion des expériences qui produisent dans l'élève un véritable intérêt pour l'apprentissage de la langue étrangère.

Mots-clés: lecture, écriture, méthodes, médiations, stratégies d'apprentissage.

proyectos de investigación en la Facultad de Educación y miembro activo del grupo de Culturas Universitarias de la universidad. Reconocimiento Universidad la Gran Colombia por sus excelentes condiciones como docente de la Facultad de Educación. Correo electrónico: carlosf.herrera@uan.edu.co

***: Magíster en Educación de la Universidad Antonio Nariño. Tecnólogo en Comunicaciones ITEC (Convenio Telecom-Northern Alberta Institute of Technology [Canadá]). Licenciado en Educación Artística con énfasis en Danza y Teatro de la Universidad Antonio Nariño. Docente de la Facultad de Educación, vinculado al grupo de Culturas Universitarias de la universidad y miembro de la red de investigaciones UxTIC. Correo electrónico: jorgepenam@uan.edu.co 


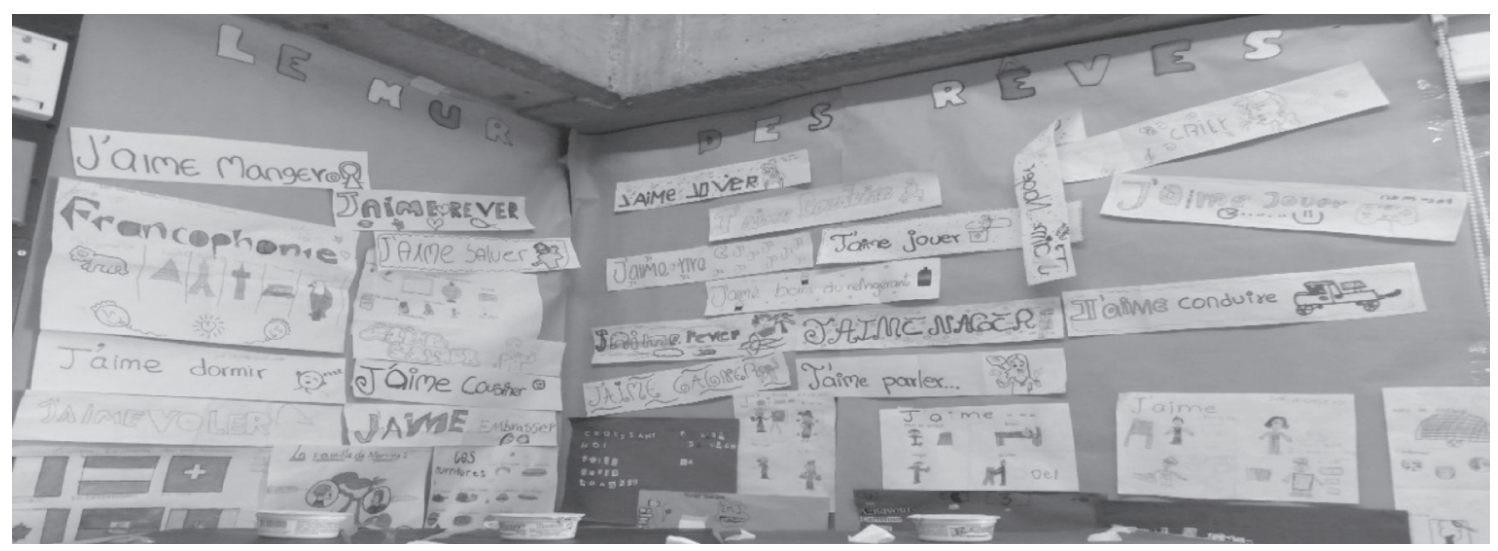

"J'écris pour pouvoir lire ce que je ne sais pas que j’allais écrire"1.

Claude Roy

\section{Introducción}

En el aprendizaje de un idioma es importante reflexionar sobre los procesos y situaciones en torno a la enseñanza de la lengua, las habilidades comunicativas, el rol del docente y los contenidos lingüísticos; los cuales están orientados, según el Marco Común Europeo de Referencia, para contribuir a una adecuada enseñanza que promueva dicha interrelación y propicie escenarios de investigación sobre la construcción y transmisión del conocimiento. Con este propósito se hace necesario describir las prácticas pedagógicas en relación con los métodos, las mediaciones y las estrategias de aprendizaje en los procesos de lectoescritura de las instituciones oficiales y privadas de Bogotá. Así mismo, cobra valor la necesidad de identificar y caracterizar las prácticas docentes en las que se asumen procesos de escritura y de lectura, sus intenciones, concepciones, roles, recursos que llevan a adelantar, devolverse, suspender, reflexionar, sintetizar y relacionar información previa con la nueva. Desde esta perspectiva, se espera que los resultados de la investigación permitan un ejercicio metacognitivo en cuanto al rol del docente y sus prácticas educativas, lo que llevará a fortalecer todos los aspectos relacionados con la enseñanza de la lengua estudiada.

\section{La enseñanza del francés en instituciones oficiales y privadas de Bogotá}

Esta investigación buscó determinar las prácticas de lectura y escritura en relación con los procesos de enseñanza de una lengua extranjera. En ese sentido, se observaron las prácticas pedagógicas del francés propiamente en instituciones oficiales y privadas de Bogotá, con el fin de establecer las tendencias pedagógicas que posibilitan nuevas didácticas, mediaciones y estrategias de aprendizaje para el conocimiento de la lengua extranjera y acercamientos a la cultura estudiada. En ese orden de ideas, abordar la didáctica de las lenguas en torno a las competencias de la lectura y la escritura remite a reevaluar las prácticas pedagógicas en el aula, para un desarrollo significativo en los procesos de lectoescritura, a fin de facilitar la comprensión de la lengua y despertar el interés de los educandos a través de la creación de mundos posibles, entre otros. Así mismo, se resalta el rol del docente en la selección, planeación y orientación constante en las actividades desarrolladas en el aula para la promoción de dichas habilidades y/o competencias.

\footnotetext{
"Escribo para poder leer lo que no sabía que iba a escribir" (la traducción es de los autores).
} 


\section{Metodología de la investigación enfocada hacia la lectoescritura}

La metodología desarrollada en la investigación fue la cualitativa descriptiva, en la que se llevó a cabo una observación directa en el aula de clases a cada una de las instituciones, además de la realización de veinte entrevistas semiestructuradas a directivos y docentes

Gráfica 1. Técnicas de recolección de la información

Técnicas de recolección de la información

Ficha de caracterización institucional

Observación directa no participante

Fotografías

Diarios de campo

Entrevista semiestructurada

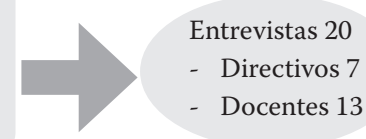

Fuente: elaboración propia

\section{Población}

Gráfica 2. Instituciones educativas participantes y sus localidades

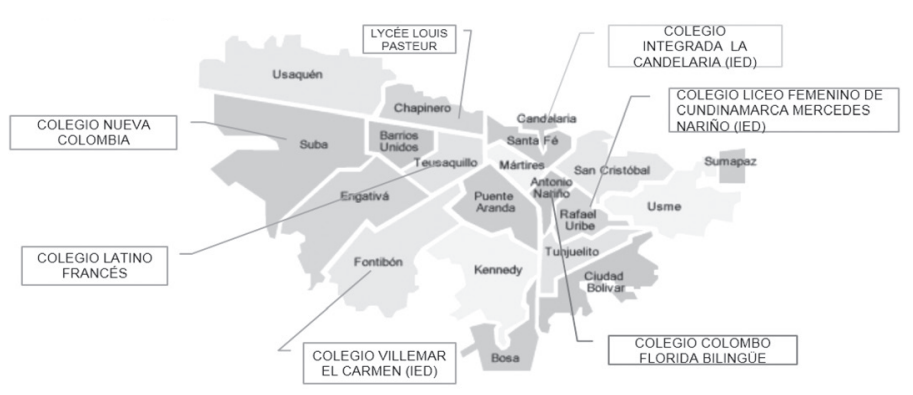

Fuente: elaboración propia de lengua extranjera, la elaboración de siete fichas de caracterización institucional y diarios de campo; estos fueron los instrumentos utilizados en la recopilación de la información. Las imágenes fotográficas sobre los materiales y los trabajos realizados por los estudiantes sirvieron como evidencia en la recolección de la información relacionada con los procesos de lectoescritura. Lo anterior permitió al grupo de investigadores identificar una variedad de métodos, mediaciones y estrategias de aprendizaje que posibilitan la enseñanza del idioma extranjero; además de considerar tendencias hacia el aprendizaje significativo, de acuerdo con las necesidades educativas de la población y el énfasis de las instituciones.
Los agentes participantes en esta investigación fueron los docentes de lengua francesa y directivos de cuatro instituciones oficiales y tres instituciones privadas en Bogotá, de las localidades Chapinero, La Candelaria, Fontibón, Rafael Uribe Uribe, Suba, San Cristóbal y Teusaquillo. Las instituciones educativas cuentan con diversos énfasis institucionales; entre los que se destaca la lengua extranjera, las humanidades, el turismo y el patrimonio propiamente.

\section{Los métodos de enseñanza de las lenguas extranjeras}

Para abordar los métodos es necesario definir este término partiendo de la concepción que establece el Instituto Cervantes, citada por Núñez Delgado y Santamarina Sancho (2015):

Un método es un conjunto de procedimientos, establecidos a partir de un enfoque para determinar el programa de enseñanza, sus objetivos, sus contenidos, las técnicas de trabajo, los tipos de actividades, y los respectivos papeles y funciones de profesores, alumnos y materiales didácticos.

Estas dos autoras, en su artículo Enfoques, métodos y metodología para el desarrollo de la competencia en comunicación lingüística confirman la importancia de articular el ambiente de trabajo y los objetivos propuestos como un reto para los docentes y como base de la formación de las competencias profesionales (p. 10). 
En ese sentido, se hace necesario renovar constantemente los métodos y el rol de los docentes para que se ajusten a los diversos objetivos propuestos y se promuevan las competencias comunicativas de acuerdo con contextos propios de la lengua estudiada y de la lengua materna en la que se favorezca la inclusión, la interculturalidad y, por ende, la formación de ciudadanos críticos como seres sociales. Al respecto, el 30\% de los entrevistados asegura que para el aprendizaje de la lengua extranjera se hace necesario tener bases sólidas de la lengua materna para profundizar en actividades propias de lectoescritura. De ese número, el $50 \%$ asevera que el aspecto gramatical resulta importante en la interpretación de textos, siempre y cuando se contextualice mediante la preparación de diversas actividades que promuevan el uso de la lengua. En todos los colegios visitados se realizan actividades que cumplen con este objetivo, tales como: Le jour de la Francophonie, Mardi Gras, la fête du chandeleur, Paris en Villemar, Exposición de los monumentos más representativos de la cultura francesa, Ciclo de cine francés, Karaoke, Correspondencia virtual con Francia, Día de la interculturalidad, entre otras.

De esta manera, el método y la metodología empleados en el diseño, preparación y presentación de estas actividades se articulan con el ánimo de desarrollar la competencia comunicativa tanto en las habilidades orales como escritas. En este sentido, se observa que el 100\% de las instituciones genera espacios donde los estudiantes construyen el conocimiento a través de experiencias significativas en las que los conocimientos previos son vinculados con los nuevos en contextos relacionados con el entorno familiar, social, académico y cultural.

El estudio mostró que las instituciones participantes utilizan métodos tales como el tradicional, el audiolingual, la respuesta física total, el enfoque comunicativo y el ecléctico para abordar las prácticas de lectura y escritura, según los objetivos trazados en concordancia con las necesidades de la población estudiantil. Un 5\% de los entrevistados, por ejemplo, utiliza el método tradicional para vincular las prácticas de lectura y escritura, el cual se limita al desarrollo y solución de ejercicios de gramática. En este caso, no se evidencia un proceso de comprensión lectora ni tampoco de producción textual. Un 10\% emplea el método audiolingual, basado principalmente en la repetición de palabras e interés en la fonética. En relación con la respuesta física total, otro $10 \%$ recurre a las órdenes verbales para que los estudiantes de primeros años de primaria sigan instrucciones a través de la expresión corporal. De este modo, se apropian del vocabulario para luego realizar actividades

Gráfica 3. Ejemplos de algunas de las actividades y concursos realizados en las instituciones participantes.

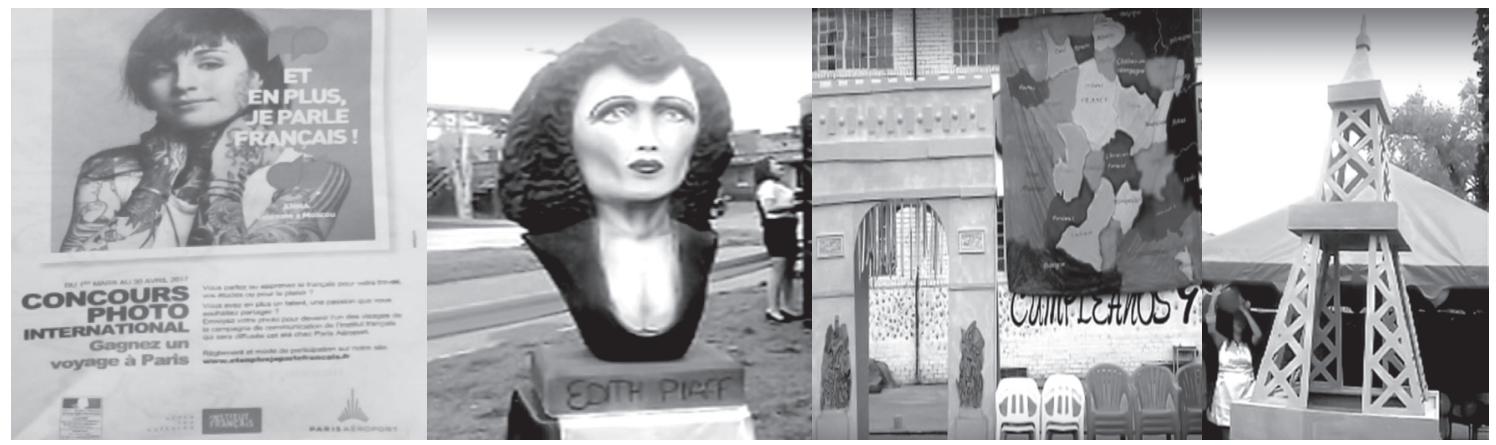

Fuente: fotos tomadas de las instituciones visitadas y vídeos realizados por los estudiantes subidos en la web https://

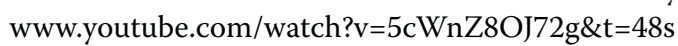


asociadas especialmente a la lectura de imágenes. Otro de los métodos más utilizados por parte de estas instituciones es el enfoque comunicativo, en el que un $70 \%$ centra su atención en el desarrollo de la competencia comunicativa. Cabe resaltar que un $5 \%$ se vale del método ecléctico, es decir, la combinación de varios métodos para promover actividades asociadas con la lectura y la escritura.

Estos métodos dan lugar al desarrollo de competencias de lectura y escritura donde el docente proporciona las herramientas para que los estudiantes se motiven a crear, diseñar y producir discursos en diversas situaciones comunicativas y contextos reales desde la socioafectividad y el fortalecimiento de la autoestima, lo cual les permite ser más conscientes de su propio aprendizaje de la lengua. Así mismo, favorecen la interdisciplinariedad entre diferentes áreas del conocimiento; tales como, la literatura, las ciencias sociales, la música, entre otras.

\section{Las mediaciones de la lectura y la escritura}

De acuerdo con los lineamientos curriculares para el área de Idiomas Extranjeros, establecidos por el Ministerio de Educación Nacional, 'se requieren 'lectores' competentes que puedan responder a la exigencia contemporánea multimedial que avanza a pasos vertiginosos" (Ministerio de Educación Nacional, 2017). En este sentido, el 30\% de los colegios que participaron en el desarrollo de esta investigación cuenta con tableros inteligentes que favorecen la formación de dichos lectores competentes, pero, son más las instituciones visitadas que carecen de este valioso tipo de recursos. Desde esta perspectiva, cabe resaltar que la lectura de textos interactivos

Gráfica 4. Material exclusivo para la enseñanza de la lengua francesa utilizado por algunas de las instituciones participantes.

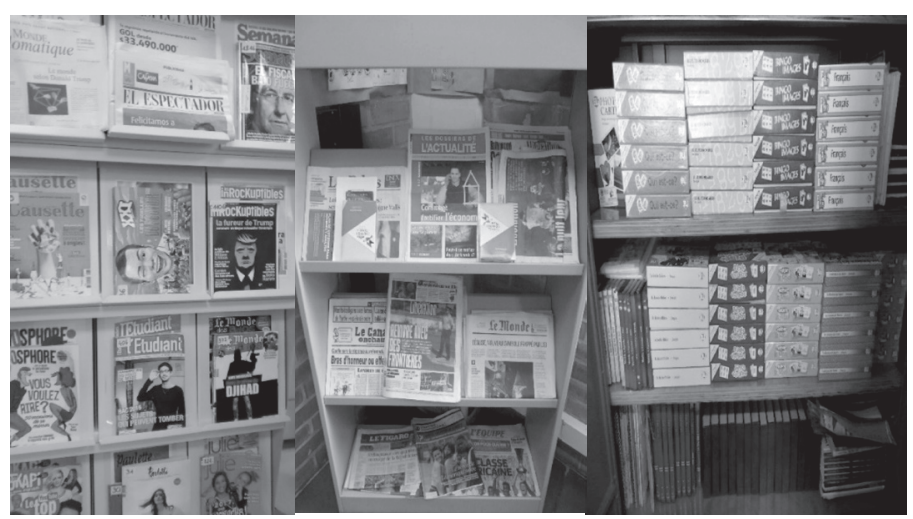

Fuente: fotografías tomadas directamente del material impreso de las instituciones participantes. posibilita la producción escrita en diferentes formatos, enriquecida a la vez por la comunicación entre los estudiantes que trabajan en equipo y por la información suministrada por textos digitales. Entre los recursos más utilizados por los docentes participantes se encuentran el uso de páginas virtuales, tales como Le Point du Fle, Duolinguo, Françaventure, entre otras, y material exclusivo para la enseñanza de la lengua. De acuerdo con lo anterior, estas páginas permiten una interacción constante con el idioma a través de la virtualidad que los acerca a desarrollar diversos tipos de ejercicios, desde la gramática, la comprensión de textos, la incorporación de nuevo vocabulario y preparación en los exámenes de lengua exigidos según el Marco Común Europeo de referencia de las lenguas.

Asimismo, un 20\% de los docentes participantes asevera propiciar escenarios asociados a las aulas de inmersión y hacer uso de material novedoso, auténtico, especializado, proporcionado por la Alianza Francesa mediante la modalidad de inscripción en la biblioteca. Por otra parte, un $30 \%$ de las instituciones cuenta con una colección de juegos en lengua francesa para las aulas de inmersión y dos maletas viajeras, cada una con diez computadoras proporcionadas por la Secretaría de Educación y otros juegos elaborados por practicantes de las universidades. El 20\% de los entrevistados 
resaltó que durante el periodo de cooperación educativa por parte de la Embajada Francesa, a través del agregado cultural, Adelino Braz, las instituciones recibieron material didáctico relacionado con juegos interactivos multimedias y juegos de mesa, como loterías, flashcards, entre otros, relacionados con la enseñanza de la lengua.

\section{Estrategias de aprendizaje a través de la lectura y la escritura en la lengua extranjera}

Las estrategias de aprendizaje juegan un papel importante en el proceso de enseñanza $\mathrm{y}$ aprendizaje de una lengua extranjera. Al respecto, Valiente (2006, p. 116) afirma que estas son "acciones y operaciones tácticas que realizan los alumnos ante una tarea de comprensión" y que son tan importantes como los contenidos. Desde esta perspectiva, las instituciones participantes aseveran que las estrategias de lectura y escritura manifestadas en las diversas actividades de lengua realizadas en el aula y fuera de ella contribuyen al desarrollo de las competencias comunicativas, promueven el aprendizaje autónomo y permiten al docente asumir un doble rol, como guía y colaborador en el proceso de enseñanza de la lengua extranjera.

Por otra parte, Oxford (1990) hace alusión a las estrategias metacognitivas; estas se enfocan en el autocontrol y en la preparación previa de los componentes lingüísticos. Entre las más utilizadas en el ámbito escolar se pueden citar: la atención dirigida (concentrarse en la tarea de aprendizaje), atención selectiva (concentrarse en aspectos específicos de la lengua), autocontrol (toma de conciencia sobre el proceso de aprendizaje), automonitorización (corregir la producción propia) y autoevaluación (evaluar el producto de su propio aprendizaje). En este sentido, se encontró que el 100\% de los docentes participantes de las instituciones de básica primaria utiliza las estrategias de memoria, como la recurrencia a la imaginación crítica, en la que los estudiantes relacionan la nueva información con conocimientos previos a través de imágenes visuales, el uso de palabras clave, en la que se relaciona una nueva palabra con una que les es familiar a través de la creación de diálogos contextualizados en el entorno propio de los estudiantes.

Desde otra perspectiva, se constató el uso de estrategias cognitivas, las cuales posibilitan la repetición (prácticas en voz alta), traducción (uso de la lengua materna) para entender y producir en la lengua objeto de estudio, agrupamiento (reordenar y clasificar información), apuntes (tomar nota de la idea principal), deducción (identificar y aplicar reglas de la segunda lengua), recombinación (producir a partir de elementos conocidos) e imágenes (relacionar la nueva información con estas [Oxford, 1990]). Entre las estrategias cognitivas utilizadas por los docentes de francés se encontró que el 100\% hace uso de estas para llevar a cabo el desarrollo de las tareas y proyectos de lengua, las cuales se encuentran centradas en el aprendizaje de los estudiantes.

De acuerdo con lo anterior, la lectura y la escritura son herramientas fundamentales para acceder al conocimiento. Las manifestaciones escritas son evidencia de procesos de desarrollo y consolidación culturales; además, el ámbito educativo requiere de ellas para dar cuenta de cómo interactúan en la construcción de saberes. En ese sentido, los procesos de lectura y escritura permean todas las áreas del conocimiento y obedecen al pensamiento superior complejo. Desde esa perspectiva se hace necesario entonces que las instituciones de educación básica y media donde se enseña francés les den a estas dos habilidades comunicativas un papel preponderante en los procesos de enseñanza de esta lengua extranjera. 


\section{Conclusión}

La variedad de métodos, mediaciones y estrategias de aprendizaje encontradas hacen que este estudio concluya que es necesario reevaluar las prácticas pedagógicas para el fortalecimiento de las competencias comunicativas en la enseñanza del idioma francés, en las que se propicien nuevas formas de leer y escribir que se correspondan con el desarrollo de las tecnologías de la información y la comunicación.

Desde los métodos se hace necesario concientizar a los docentes sobre la importancia de la interacción de los estudiantes con respecto a la virtualidad, propiciando así un trabajo autónomo para potencializar habilidades de lectura y escritura en formatos diferentes al texto impreso. Además, cabe resaltar que los docentes deben constantemente innovar sus prácticas pedagógicas a través de procedimientos, enfoques y estrategias que contribuyan a potencializar los procesos de enseñanza de la lengua. Vale la pena resaltar que las estrategias lectoras adoptadas por las instituciones son determinantes para que los estudiantes de lengua francesa pasen de la comprensión a la producción de textos, conscientes de que su escritura (siempre en mejoramiento) encontrará interlocutores que participan de procesos de aprendizaje y desarrollo del pensamiento.

Finalmente se resalta que es necesario tener en cuenta los referentes legales e, igualmente, las concepciones metodológicas en torno a las prácticas de lectura y escritura. Al respecto, los docentes deben enfocar sus procesos en correspondencia con los lineamientos curriculares, las políticas educativas y los estándares del Marco Común Europeo para las lenguas extranjeras.

\section{Referencias}

Ministerio de Educación Nacional. (2017). Lineamientos curriculares Idiomas Extranjeros. Tomado de https://www.mineducacion. gov.co/1759/articles-339975_recurso_7.pdf

Núñez Delgado, P. y Santamarina Sancho, M. (2015). Enfoques, métodos y metodología para el desarrollo de la competencia en comunicación lingüística. En Núñez Delgado, P. (Ed.). Innovación docente en didáctica de la lengua y la literatura: teoría e investigación. España: Editorial Octaedro.
Oxford, R. L. (1990). Language Learning Strategies. What every teacher should know. Boston: Heinle \& Heinle Publishers

Valiente, J. M. J. (2006). Estrategias de enseñanza-aprendizaje en la comprensión oral del francés como segunda lengua en la universidad. Madrid, ES: Universidad Complutense de Madrid. Retrieved from http://www.ebrary. com 